\title{
A GROWTH MINDSET PILOT INTERVENTION FOR A GRADUATE-LEVEL BIOSTATISTICS COURSE
}

\author{
BETTY S. LAI \\ Department of Counseling, Developmental, and Educational Psychology \\ Lynch School of Education, Boston College \\ betty.lai@bc.edu \\ MICHELLE S. LIVINGS \\ Department of Population Health Sciences, School of Public Health \\ Georgia State University \\ mlivingsl@student.gsu.edu \\ MICHELLE P. D'AMICO \\ Department of Population Health Sciences, School of Public Health \\ Georgia State University \\ mlee119@student.gsu.edu \\ MATTHEW J. HAYAT \\ Department of Population Health Sciences, School of Public Health \\ Georgia State University \\ mhayat@gsu.edu \\ JEREMIAH WILLIAMS \\ Department of Population Health Sciences, School of Public Health \\ Georgia State University \\ jwilliams293@student.gsu.edu
}

\begin{abstract}
A growth mindset emphasizes the malleability of intelligence. The purpose of this pilot study was to implement and evaluate a growth mindset intervention for graduate students. Participants were twenty graduate students recruited from an introductory public health biostatistics class. Students were assessed three times during one semester. At each time point, students completed assessments of growth mindset, grit, social and emotional health, and attitudes toward statistics. Student grades were collected from the course instructor. Descriptive results indicate that growth mindset, grit, and social and emotional health fluctuated little over time. Mean scores for four attitudes toward statistics components improved over time. We found limited relationships between growth mindset and final grades. Growth mindset-based strategies may be more impactful at a persona, rather than academic, level.
\end{abstract}

Keywords: Statistics education research; Persistence; Psychoeducation; Grit

\section{INTRODUCTION}

Statistics is a fundamental course for studies in many disciplines, including public health (Davis, Dandoy, \& Greaves, 2003), psychology (Rossen \& Oakland, 2008), and sociology (Shin, 1975). Yet many graduate students have anxiety about statistics (Onwuegbuzie \& Wilson, 2003) that may adversely impact their academic performance in these foundational courses (Onwuegbuzie, 2003). Changing attitudes toward learning statistics while also improving academic outcomes is an ongoing challenge for instructors (Chew \& Dillon, 2014). One promising area for increasing motivation and

Statistics Education Research Journal, 17(2), 104-119, http://www.stat.auckland.ac.nz/serj

(C) International Association for Statistical Education (IASE/ISI), November, 2018 
achievement related to statistics is mindset research. The implicit theory of intelligence defines a growth mindset as having the view that intelligence is malleable (Dweck, Chiu, \& Hong, 1995). Challenges or failures offer opportunities for intellectual growth. Conversely, a fixed mindset perspective views intelligence as static or incapable of changing.

Students' mindsets have been linked to learning outcomes. Blackwell, Trzesniewski, and Dweck (2007) conducted a longitudinal study of middle school students and found that students who believed in the malleability of intelligence at the outset of the study achieved better mathematics grades over the next two years relative to their fixed mindset counterparts. Among college students facing setbacks, having a growth mindset about intelligence was linked with the belief that low-achieving students could develop their academic abilities in the future (Aditomo, 2015). Additionally, a survey of adult learners aged 18 to 74 found that individuals with a growth mindset may have more productive study and learning habits into adulthood (Yan, Thai, \& Bjork, 2014).

Evidence demonstrates that growth mindset interventions may be effective in changing students' mindsets and improving outcomes among students in the elementary to college age groups. Carol Dweck (2010), the seminal researcher on growth mindsets, notes that based on her work there are four steps involved in changing mindsets: 1) learn to hear your fixed mindset "voice"; 2) recognize that you have a choice (i.e., interpretation matters); 3) talk back with a growth mindset voice (i.e., cognitive restructuring); and 4) take a growth mindset action, including learning from setbacks. Interventions designed to change students' mindsets have focused primarily on psychoeducation (Blackwell et al., 2007; Good, Aronson, \& Inzlicht, 2003; Yeager et al., 2016). Psychoeducation is a concept adapted from therapies for mental illness (Bäuml, Froböse, Kraemer, Rentrop, \& Pitschel-Walz, 2006). In the context of growth mindset intervention research, psychoeducation consists of teaching students about the basics of brain function, how the brain changes through learning, and techniques for studying and learning. Writing exercises are also incorporated into the curriculum to promote self-reflection and internalization of messages (Yeager et al., 2016).

Examples of studies that investigate growth mindset interventions include a study conducted by Good et al. (2003). Good and colleagues implemented a growth mindset intervention among middle school students. The intervention condition included two 90-minute sessions with a mentor that featured messages about the "expandable nature of intelligence" (p. 653), and students also had opportunities to communicate with the mentor over weekly email correspondence. Mentors also worked with students to design and create a web page that included growth mindset messages. The intervention resulted in associated increases in student motivation and superior academic outcomes over time compared with a control group that received no intervention.

In a second example, high school students receiving a growth mindset intervention experienced increased motivation, persistence, and self-efficacy, with a particularly marked improvement in mathematics grades (Paunesku et al., 2015). This intervention was delivered via a single online module completed in 45 minutes. The session focused on implications of neuroscience for students to become more intelligent through "study and practice" (p. 3), and was followed by two writing exercises.

Several other studies have examined the effects of growth mindset interventions among high school or undergraduate college students. High school students in one growth mindset intervention improved their grade point averages and course-passing rates relative to their peers who did not receive the intervention (Yeager et al., 2016). Among African American undergraduate students, an intervention emphasizing the malleability of intelligence was associated with increases in academic engagement, enjoyment, and grade point average relative to their peers in the control group, mitigating the negative effects of stereotype threat (Aronson, Fried, \& Good, 2002). Among undergraduate statistics students, female recipients of growth-mindset training were more likely to report a positive change in how they valued statistics than their male counterparts (Zonnefeld, 2015). Finally, among undergraduate science, technology, engineering, and mathematics students who received a growth mindset intervention in a pre-calculus course, all participants considered themselves to have growth mindsets toward intelligence and mathematical ability at the end of the intervention (Kassaee, 2017).

Additional factors may influence students' mindsets and academic outcomes. One such factor is grit, or perseverance and passion, toward long-term goals (Duckworth, Peterson, Matthews, \& Kelly, 2007a). Previous research has discussed suggestions and specific steps to enhance both grit and growth mindset (Fitzgerald \& Laurian-Fitzgerald, 2016; Hochanadel \& Finamore, 2015). Further, one of these studies investigated both grit and growth mindset in relation to academic outcomes, finding that students 
with more grit and a growth mindset are better able to overcome challenges and reach academic goals (Hochanadel \& Finamore, 2015).

Various studies have demonstrated the direct relationship between grit and academic outcomes using the Grit Scale (Duckworth, Peterson, Matthews, \& Kelly, 2007b) and the Short Grit Scale (GritS; Duckworth \& Quinn, 2009). For example, adults with more education had more grit than adults of the same age with less education (Duckworth et al., 2007a). Undergraduate students with more grit had higher grade point averages than their classmates with less grit (Duckworth et al., 2007a). Grittier high school students were more likely to graduate compared to counterparts with less grit (Eskreis-Winkler, Shulman, Beal, \& Duckworth, 2014).

Social-emotional health is a second factor that may impact academic outcomes. Social-emotional competence has been widely described as a "critical factor" to target via interventions in schools because of associations with behavioral and academic outcomes (Domitrovich, Durlak, Staley, \& Weissberg, 2017). Interventions designed to improve students' social-emotional health (known as "social-emotional learning") have been linked to improvements in students' attitudes, as well as improvements in academic outcomes (Durlak, Weissberg, Dymnicki, Taylor, \& Schellinger, 2011; Taylor, Oberle, Durlak, \& Weissberg, 2017; You et al., 2014). Such interventions have been implemented and studied with students of various ages, from kindergarten through high school (Durlak et al., 2011; Taylor et al., 2017). One social-emotional health construct in particular-covitality, defined as the "synergistic effect of positive mental health resulting from the interplay among multiple positive psychological building blocks" (You et al., 2014, p. 1000) - has been directly linked to course grades among high school students (You et al., 2014).

Finally, students' attitudes toward statistics may play a role in academic outcomes, particularly in statistics courses. The extant literature shows that, among undergraduates, students with positive attitudes toward statistics are more likely to perform well in statistics courses, whereas negative attitudes toward statistics are often associated with poorer academic performance (Evans, 2007; Gal \& Ginsburg, 1994; Kiekkas et al., 2015; Nolan, Beran, \& Hecker, 2012). However, there has been no previous research investigating whether students' attitudes toward statistics are associated with students' mindsets. A relationship between mindset and attitudes toward statistics may further predict academic performance and academic outcomes.

\section{STUDY PURPOSE}

To date, limited research has examined whether growth mindset interventions may be implemented and effective in graduate-level education. Further research is needed to examine whether a growth mindset intervention at the graduate level might alleviate anxiety and encourage motivation in the face of challenges related to statistics. Thus, the purpose of this study was to develop and pilot-test a growth mindset intervention for a graduate level introductory biostatistics course in a school of public health. The intervention included psychoeducation activities. Aspects measured by means of self-report questionnaires included growth mindset, grit, social-emotional health, and attitudes toward statistics; these aspects were selected for inclusion in the study questionnaire because of their associations with academic outcomes.

This paper presents descriptive results from our growth mindset pilot intervention. Study hypotheses were as follows:

i. Students' self-assessed growth mindset, grit, social and emotional health, and attitudes toward statistics would improve.

ii. Students' growth mindsets would be positively associated with academic outcomes (i.e., final course grades).

iii. Students' perceptions of the feasibility, acceptability, and utility of the intervention would be positive. 


\section{METHODS}

\subsection{PARTICIPANTS}

Participants were graduate students recruited during the spring semester from an introductory graduate biostatistics course in public health. This course is a statistics course focused on public health and the health sciences. In this paper, the terms statistics and biostatistics are used interchangeably. Both terms in this paper indicate statistics with a health focus. The biostatistics course described in this work is a core course for public health graduate students covering basic probability, random variation, and univariate and bivariate descriptive and inferential statistical techniques. The course seeks to foster critical evaluation of statistical analyses in public health. There is no required prerequisite coursework for admission to our public health program. Thus, students' educational backgrounds and prior exposure to statistics vary greatly, ranging from no formal statistical training to completion of university or even graduate-level coursework in the subject.

In a class of 25 students, 20 signed consent forms. Of those who consented, 20 participated at Time 1 , and 18 of these students participated at all three study time points, though completion rates of the specific measures at each time point varied. Two participants withdrew from the course during the term; their information up to the point of withdrawal was included in this study (one of these students completed only the Time 1 questionnaire, whereas the other student completed questionnaires at Time 1 and Time 2). Five students declined to participate but did not provide reasons for their decision. Participant demographics at Time 1 are shown in Table 1. The majority of participants were female, non-Hispanic Black, middle class, US citizens in their first year of graduate school. Participants' ages ranged from 22 to 50 years $(M=28.10, S D=7.20)$. The number of high school mathematics and/or statistics courses completed by participants by the beginning of this study ranged from 2 to $10(M=$ $5.00, S D=2.09$ ); the number of undergraduate mathematics and/or statistics courses completed also ranged from 2 to $10,(M=4.18, S D=2.24)$.

Table 1. Participant demographics at Time $1(N=20)$

\begin{tabular}{|c|c|c|c|c|c|}
\hline Demographic & $n$ & $\%$ & Demographic & $n$ & $\%$ \\
\hline Gender & & & Parents' Socioeconomic Status & & \\
\hline Female & 16 & 80.0 & Working Class & 1 & 5.0 \\
\hline Male & 4 & 20.0 & Lower-Middle Class & 5 & 25.0 \\
\hline Race \& Ethnicity & & & Middle Class & 9 & 45.0 \\
\hline Non-Hispanic Black & 10 & 50.0 & Upper-Middle Class & 5 & 25.0 \\
\hline Non-Hispanic White & 6 & 30.0 & Degree Concentration & & \\
\hline Non-Hispanic Asian & 3 & 15.0 & Biostatistics & 1 & 5.0 \\
\hline Hispanic, Unidentified & 1 & 5.0 & Environmental Health & 2 & 10.0 \\
\hline U.S. Citizen & 16 & 80.0 & Epidemiology & 7 & 35.0 \\
\hline Native English Speaker & 17 & 85.0 & Health Management \& Policy & 4 & 20.0 \\
\hline Birthplace & & & Health Promotion \& Behavior & 5 & 25.0 \\
\hline Georgia & 3 & 15.0 & Other & 1 & 5.0 \\
\hline Other U.S. State & 11 & 55.0 & & & \\
\hline International & 6 & 30.0 & & & \\
\hline
\end{tabular}

Given this was a pilot study, a one-group design was used. A control group was not included in the design of the study. The study sample size (20) was too small to provide adequate power to assess outcomes between groups. This pilot study was conducted with the intention of descriptively analyzing results from one small group of students and with the potential to conduct a follow-up study implementing the same interventions in a larger group of students.

\subsection{PROCEDURE}

The Institutional Review Board for Georgia State University approved this study. Self-report paper and pencil questionnaires were administered at the first class session (Time 1), the course midpoint (Time 2, after the first of three exams, and after seven intervention activities had occurred - note that 
exam growth mindset activities were repeated), and the end of term (Time 3 ). The questionnaires took approximately 20 minutes to complete. To avoid coercion, the instructor was not present in the classroom when questionnaires were administered.

\subsection{INTERVENTION}

Design of the pilot intervention occurred over the course of the fall 2016 semester. In designing the intervention, we made the following decisions: i) all intervention-related activities would be short, 510 minute activities, to avoid disrupting course content; ii) activities would be presented at the start of class; and iii) intervention activities would focus on psychoeducation. Over the 14 three-hour class sessions for the course, nine intervention activities were presented (see Table 2). To connect these

Table 2. Growth mindset-related activities utilized during the pilot study

\begin{tabular}{|c|c|c|c|}
\hline Timing & Activities & Description & Time allotted \\
\hline \multirow[t]{3}{*}{$\begin{array}{l}\text { Beginning of } \\
\text { course }\end{array}$} & $\begin{array}{l}\text { Teacher introduction of growth } \\
\text { mindset concepts }\end{array}$ & Review handout with examples. & $5-10$ minutes \\
\hline & $\begin{array}{l}\text { Watch two videos: } \\
\text { 1) Fixed and Growth Mindset } \\
\text { (Bryan University, 2016), } \\
\text { 2) The Importance of Work by } \\
\text { Ira Glass (Krause, 2017) }\end{array}$ & $\begin{array}{l}\text { Group Discussion: How do you } \\
\text { define intelligence? What are some } \\
\text { commonly fixed mindset } \\
\text { statements? }\end{array}$ & 10 minutes \\
\hline & Cognitive restructuring task & $\begin{array}{l}\text { Assess and rephrase mindsets } \\
\text { using self-talk. Identify fixed } \\
\text { mindset statements and reframe } \\
\text { using growth mindset statements } \\
\text { (group activity). }\end{array}$ & $5-10$ minutes \\
\hline \multirow[t]{2}{*}{$\begin{array}{l}\text { Around the } \\
\text { three course } \\
\text { exams }\end{array}$} & $\begin{array}{l}\text { Pretest mindset check-in: } \\
\text { Students asked a series of } \\
\text { questions to assess mindset and } \\
\text { gaps in understanding } \\
\text { (repeated before each exam) }\end{array}$ & $\begin{array}{l}\text { Discussion: What do you know as } \\
\text { of now? What aren't you } \\
\text { understanding? Using a growth } \\
\text { mindset, what is your strategy } \\
\text { moving forward? }\end{array}$ & $5-10$ minutes \\
\hline & $\begin{array}{l}\text { Posttest check-in: What } \\
\text { worked? } \\
\text { (repeated after each exam) }\end{array}$ & $\begin{array}{l}\text { Students were asked to share/bring } \\
\text { two resources to class that helped } \\
\text { them engage with and practice } \\
\text { material. }\end{array}$ & $5-10$ minutes \\
\hline \multirow[t]{3}{*}{$\begin{array}{l}\text { Middle of } \\
\text { course }\end{array}$} & Sharing failure and growth & $\begin{array}{l}\text { In small groups, students were } \\
\text { asked to identify times in their } \\
\text { lives or those of personal } \\
\text { friends/family in which they } \\
\text { "failed" and were able to use that } \\
\text { experience to grow. }\end{array}$ & $5-10$ minutes \\
\hline & $\begin{array}{l}\text { What is your growth mindset } \\
\text { motto? }\end{array}$ & $\begin{array}{l}\text { In small groups, students were } \\
\text { asked to identify and share growth } \\
\text { mindset mottos that motivated } \\
\text { them. }\end{array}$ & $5-10$ minutes \\
\hline & $\begin{array}{l}\text { Self-Reflection: What } \\
\text { challenge(s) have you overcome } \\
\text { in this course thus far? }\end{array}$ & $\begin{array}{l}\text { Discussion encouraged students to } \\
\text { reframe challenges as opportunities } \\
\text { for practice and growth. }\end{array}$ & $5-10$ minutes \\
\hline $\begin{array}{l}\text { Throughout the } \\
\text { course }\end{array}$ & $\begin{array}{l}\text { Cold calling: Calling on } \\
\text { students to answer questions }\end{array}$ & $\begin{array}{l}\text { The professor explained that the } \\
\text { expectation is not that students get } \\
\text { all the answers correct, but that } \\
\text { each student has a chance to } \\
\text { engage with the material, all other } \\
\text { students have a chance to see how } \\
\text { others understand the material, and } \\
\text { to provide opportunities to clarify } \\
\text { misconceptions. }\end{array}$ & $\begin{array}{l}\text { Repeated in } \\
\text { each class } \\
\text { session }\end{array}$ \\
\hline
\end{tabular}


activities to the steps outlined by Dweck in the Introduction, Step 1 activities focused both on hearing one's fixed mindset voice and on psychoeducation. In this intervention, a psychoeducation activity involved identifying "fixed mindset self-talk" and the related Step 3 activity of generating alternative "growth mindset self-talk." Fixed mindset self-talk might include saying, "I can't understand statistics." An alternative growth mindset self-talk for this phrase could be, "I can't understand statistics yet." Step 2 activities, including activities such as a "Pretest Mindset Check-in," were implemented before the next exam and encouraged students to openly discuss gaps in their understanding of the current material. Here, students were asked a series of questions that support growth mindset, such as; 1) What do you know as of now? 2) What aren't you understanding? 3) In your growth mindset, what is your strategy moving forward? This final piece addressed Step 3, talking back with a growth mindset voice, and Step 4 , taking a growth mindset action. Planning is integral to fostering a growth mindset as it coincides with goal-setting accountability (Grit-S; Duckworth \& Quinn, 2009). Open-ended activities targeting depth and application of statistical understanding have been used in previous pedagogical studies, with the effect of increases in student performance on an intervention posttest (Casleton, Beyler, Genschel, \& Wilson, 2014). Cold calling, similar to the activities described on p. 255 of Teach Like a Champion 2.0 (Lemov, 2015), was used to encourage real-time demonstrations of the need for all students to practice working through problems in order to achieve growth and mastery. Further considerations regarding the development and implementation of this intervention are discussed in Williams et al. (2018).

\subsection{MEASURES}

All questionnaire packets included the same self-report questionnaires, with two exceptions: Time 1 was the only time point to include the full demographic survey, whereas Times 2 and 3 included an abbreviated version of the demographic survey for verification purposes, and Time 3 was the only assessment to include the Acceptability, Feasibility, Utility survey. In addition to questionnaires, student grade information was obtained at the conclusion of the semester.

Growth Mindset The Implicit Theory Scale is a 12-item scale assessing attitudes toward intelligence, morality, world, and person as fixed traits (Dweck et al., 1995). The three items regarding intelligence assessed participants' mindsets (i.e., growth mindset or fixed mindset); the remaining nine items regarding morality, world, and person were not used in this study. Participants were asked to indicate their agreement to statements such as "You can learn new things, but you can't really change your basic intelligence" on a 6-point scale from 1 (Strongly Agree) to 6 (Strongly Disagree); higher scores correspond to growth mindsets, whereas lower scores correspond to fixed mindsets. In past research, this scale has yielded high internal reliability (ranging from 0.94 to 0.98 ) and test-retest reliability (0.80; Dweck et al., 1995). Internal consistency for the growth mindset measure in this study was high ( $\alpha=0.90$ at Time $1 ; \alpha=0.97$ at Time $2 ; \alpha=0.91$ at Time 3$)$.

Grit The Short Grit Scale (Grit-S; Duckworth \& Quinn, 2009) is an 8-item scale designed to measure grit. It has been tested among groups ranging in age from adolescents $(M=13.94$ years of age, $S D=1.59)$ to young adults $(M=19.05$ years of age, $S D=1.10)$ and adults $(M=45.64$ years of age, $S D$ = 11.27; Duckworth \& Quinn, 2009). Participants are asked to respond to prompts such as "Setbacks don't discourage me" or "I finish whatever I begin" with responses ranging from 1 ("Not at all like me") to 5 ("Very much like me"); higher scores correspond to more grit, whereas lower scores correspond to less grit. The Grit-S has demonstrated acceptable internal consistency (with alphas ranging from 0.73 to 0.83 across four samples) and test-retest stability (Duckworth \& Quinn, 2009). The Grit-S showed varying internal consistency in this study, $(\alpha=0.85$ at Time $1 ; \alpha=0.85$ at Time 2; $\alpha=0.66$ at Time 3 ).

Social and Emotional Health The Social Emotional Health Survey-Higher Education Scale (SEHS-HE; Furlong, You, Shishim, \& Dowdy, 2016) is a 48-item scale that assesses four latent traits: Belief in Self, Belief in Others, Emotional Competence, and Engaged Living. Participants are asked to respond to prompts such as "Generally, I feel capable of overcoming obstacles" or "I stay focused while studying despite distractions" with responses ranging from 1 (Very much unlike me) to 6 (Very much 
like me); higher scores are reflective of higher social and emotional health. The SEHS-HE, designed for use among college-age students transitioning from secondary schools into institutions of higher education, was selected for this study to capture socioemotional health amongst graduate students facing an analogous educational transition. Previous SEHS scales have used a summary score called the Covitality score, which was also used in this study. Validation of the SEHS-HE in previous studies has yielded adequate to excellent reliability for the 48-item scale (with coefficients ranging from 0.91 to 0.95 ; Furlong et al., 2016). The SEHS-HE measure showed strong internal consistency in this study, $(\alpha=0.91$ at Time $1 ; \alpha=0.93$ at Time $2 ; \alpha=0.93$ at Time 3$)$.

Attitudes Toward Statistics The 36-item Survey of Attitudes Toward Statistics (SATS-36; Schau, 2003) measures affect, cognitive competence, value, difficulty, interest, and effort as they relate to students' attitudes toward statistics. Participants are asked to respond to 36 statements such as "I will like statistics" or "I am interested in using statistics" with responses ranging from 1 (Strongly disagree) to 7 (Strongly agree); higher scores correspond with more positive attitudes. Additional items on the survey include questions related to prior mathematics achievement, prior statistics course experience, and mathematics cognitive competence. There are "pre" and "post" versions of the SATS-36, to be implemented at the beginning and end of a statistics course; in this study, the "pre" version of the SATS36 was used at all three time points. The SATS-36 has shown acceptable internal consistency in prior research, with alphas ranging from 0.68 to 0.82 across the six subscales (Tempelaar, van der Loeff, \& Gijselaers, 2007). With the exception of the difficulty subscale, the subscales in the SATS-36 measure showed internal consistency in this study, ranging from adequate to good: affect ( $\alpha=0.81$ at Time $1 ; \alpha$ $=0.79$ at Time $2 ; \alpha=0.77$ at Time 3$)$, cognitive competence $(\alpha=0.73$ at Time $1 ; \alpha=0.94$ at Time 2; $\alpha$ $=0.77$ at Time 3$)$, value $(\alpha=0.80$ at Time $1 ; \alpha=0.88$ at Time $2 ; \alpha=0.93$ at Time 3$)$, difficulty $(\alpha=$ 0.55 at Time $1 ; \alpha=0.58$ at Time $2 ; \alpha=0.64$ at Time 3 ), interest ( $\alpha=0.87$ at Time $1 ; \alpha=0.97$ at Time $2 ; \alpha=0.96$ at Time 3 ), and effort ( $\alpha=0.82$ at Time $1 ; \alpha=0.66$ at Time $2 ; \alpha=0.77$ at Time 3 ).

Acceptability, Feasibility, Utility A survey of Acceptability, Feasibility, and Utility was developed for this study. The survey consisted of 10 Likert-scale and 4 open-ended questions measuring student perceptions of acceptability, feasibility, and utility of the growth mindset intervention. Participants were asked to rate statements such as "The psychoeducation activities were effective in helping me learn course material," "I have a clear idea of how to implement what I have learned regarding the growth mindset," and "This course was based on a growth mindset philosophy" using a Likert scale ranging from 1 (Not at all) to 5 (Totally). Higher scores corresponded to more positive attitudes. This measure was only administered at Time 3. The measure demonstrated good internal consistency $(\alpha=0.84)$. Open-ended questions were also included in this measure, with the intention of highlighting which psychoeducation and open task activities were perceived as most effective in influencing positive achievement levels and how the activities might be improved.

Grades Final grades for the course were gathered from the instructor (potential range $0-100 \%$ ).

\section{RESULTS}

Means and standard deviations for each measure and subscale were examined across all three time points (see Table 3). Further, individual scores for growth mindset, grit, and covitality were plotted across all three time points (see Figure 1), as were individual scores for each of the subscales of attitudes toward statistics (see Figure 2).

Table 3 shows that the average growth mindset score stayed about the same from Time 1 to Time 2 and then decreased at Time 3, contrary to our hypothesis (i) that growth mindset scores would improve over time. The top left graph in Figure 1 shows a spaghetti plot of individual growth mindset scores over time; this plot displays the broad range of growth mindset scores among students in the sample. 
Table 3. Statistics for study measures at each time point; mean (standard deviation) displayed

\begin{tabular}{lccc}
\hline Measure (Potential Range) & ${\text { Time } 1^{\mathrm{a}}}^{\mathrm{b}}$ & ${\text { Time } 2^{\mathrm{c}}}^{\mathrm{c}}$ & ${\text { Time } 3^{\mathrm{c}}}^{\mathrm{b}}$ \\
\hline Growth Mindset (1-6) & $4.46(1.13)^{\mathrm{b}}$ & $4.41(1.43)$ & $3.94(1.54)$ \\
Grit (1-5) & $3.74(0.72)^{\mathrm{b}}$ & $3.73(0.64)$ & $3.74(0.48)$ \\
Covitality (36-216) & $178.56(17.61)^{\mathrm{c}}$ & $179.79(18.26)$ & $183.50(16.41)$ \\
Attitudes Toward Statistics (1-7) & & & \\
$\quad$ Affect & $4.20(1.34)$ & $4.70(1.34)$ & $5.08(1.10)$ \\
$\quad$ Cognitive Competence & $4.79(1.41)$ & $5.31(1.44)$ & $5.70(1.08)$ \\
$\quad$ Value & $5.48(1.26)$ & $5.83(1.13)$ & $6.04(1.00)$ \\
$\quad$ Difficulty & $3.40(0.93)$ & $3.21(0.68)$ & $3.47(0.74)$ \\
$\quad$ Interest & $5.51(1.30)$ & $5.64(1.69)$ & $5.83(1.35)$ \\
$\quad$ Effort & $6.64(0.83)$ & $6.72(0.51)$ & $6.68(0.51)$ \\
\hline
\end{tabular}

Note. One student was absent at Time 2. Two students withdrew from the course and thus did not contribute data to Time 3. These sample sizes at each time point include students who attempted but may not have completed every question in a measure.

${ }^{\mathrm{a}} n=20 ;{ }^{\mathrm{b}} n=19 ;{ }^{\mathrm{c}} n=18$.
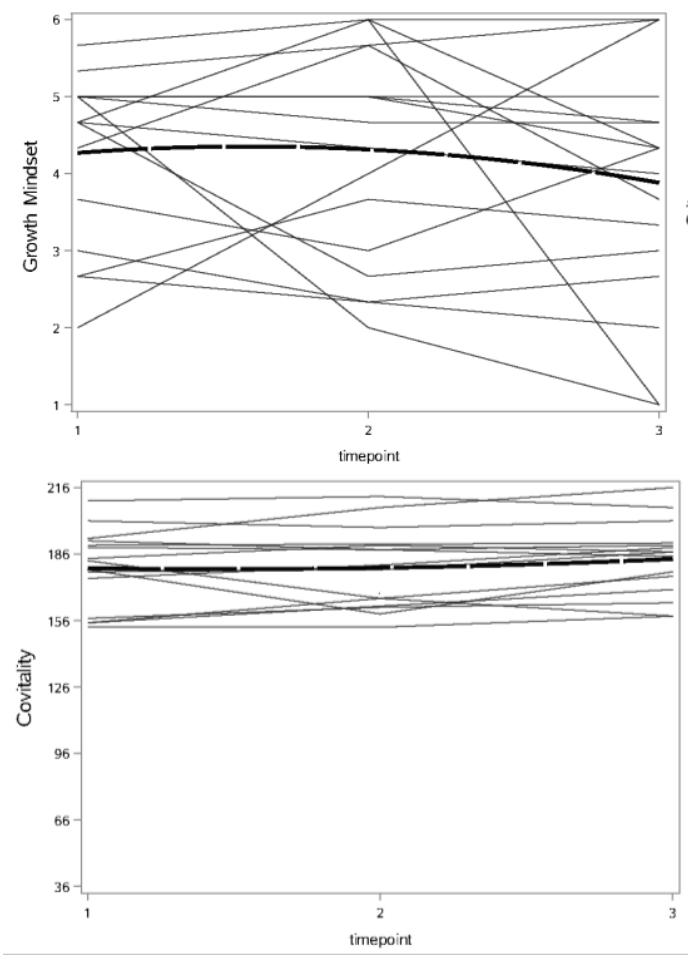

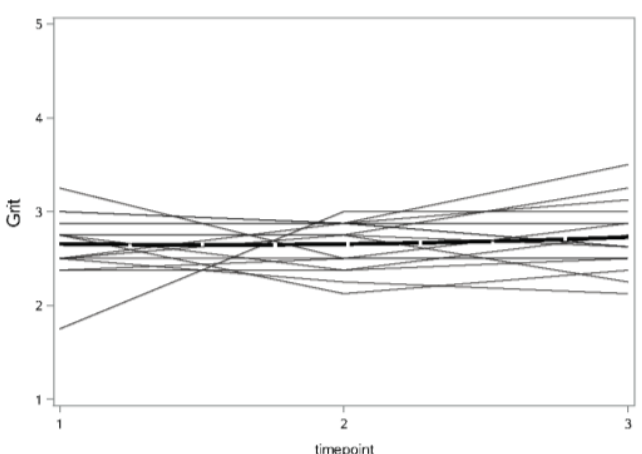

Note. Only students who provided data at three time points for a given measure are luded in the plots to depict individual change terns. Two students who dropped the course one student who was absent at Time 2 were luded from each plot due to missing data. In ition, one student who had missing covitality $\mathrm{x}$ at two time points was excluded from the d plot. Plots 1 and 2 have a sample size, refore, of $n=17$; plot 3 has a sample size of : 16. In each plot, the dashed bolded line resents the central tendency spline.

Figure 1. Spaghetti plots of individuals' growth mindset, grit, and covitality scores over time

As shown in Table 3, the average grit score was constant across all three time points, contrary to our hypothesis (i) that grit scores would improve over time. The second graph in Figure 1 shows a spaghetti plot of individual grit scores over time; this plot shows a narrow range of grit scores among students in the sample.

Covitality scores were calculated from all items on the SEHS-HE. As shown in Table 3, the average covitality score stayed about the same across all three time points, contrary to our hypothesis (i) that social and emotional health (i.e., covitality scores) would improve over time. The bottom graph in Figure 1 shows a spaghetti plot of individual covitality scores over time; although the possible score range for this measure is quite broad, this plot shows that the covitality scores among students in the sample were concentrated toward the high end of the range across all time points. 
As shown in Table 3, the average scores for four of the six SATS-36 subscales (affect, cognitive competence, value, and interest) increased steadily from Time 1 to Time 3, which supports our hypothesis (i) that attitudes toward statistics would improve over time. Interestingly, the effort and difficulty subscales were the only two SATS-36 subscales that did not steadily increase over time, contrary to hypothesis (i). The average effort score and average difficulty score stayed fairly constant across all three time points.

Figure 2 shows spaghetti plots of individual scores on each of the six SATS-36 subscales over time. The top left plot displays the broad range of affect scores among students in the sample and shows that scores generally increased over time. The middle left plot shows that cognitive competence scores were mostly clustered toward the top one-third of the score range, with one student standing out as an outlier with substantially lower scores than the rest of the group. The bottom left plot shows that value scores were mostly clustered at the high end of the subscale, with several students standing out with lower scores than the rest of the group. The top right plot shows that difficulty scores were clustered around the center of the plot. The middle right plot shows that many scores on the interest subscale were clustered toward the high end of the subscale, with several students standing out with lower scores than the rest of the group. Finally, the bottom right plot shows that the majority of students were clustered at the very top of the effort subscale, with scores between 6 and 7 .
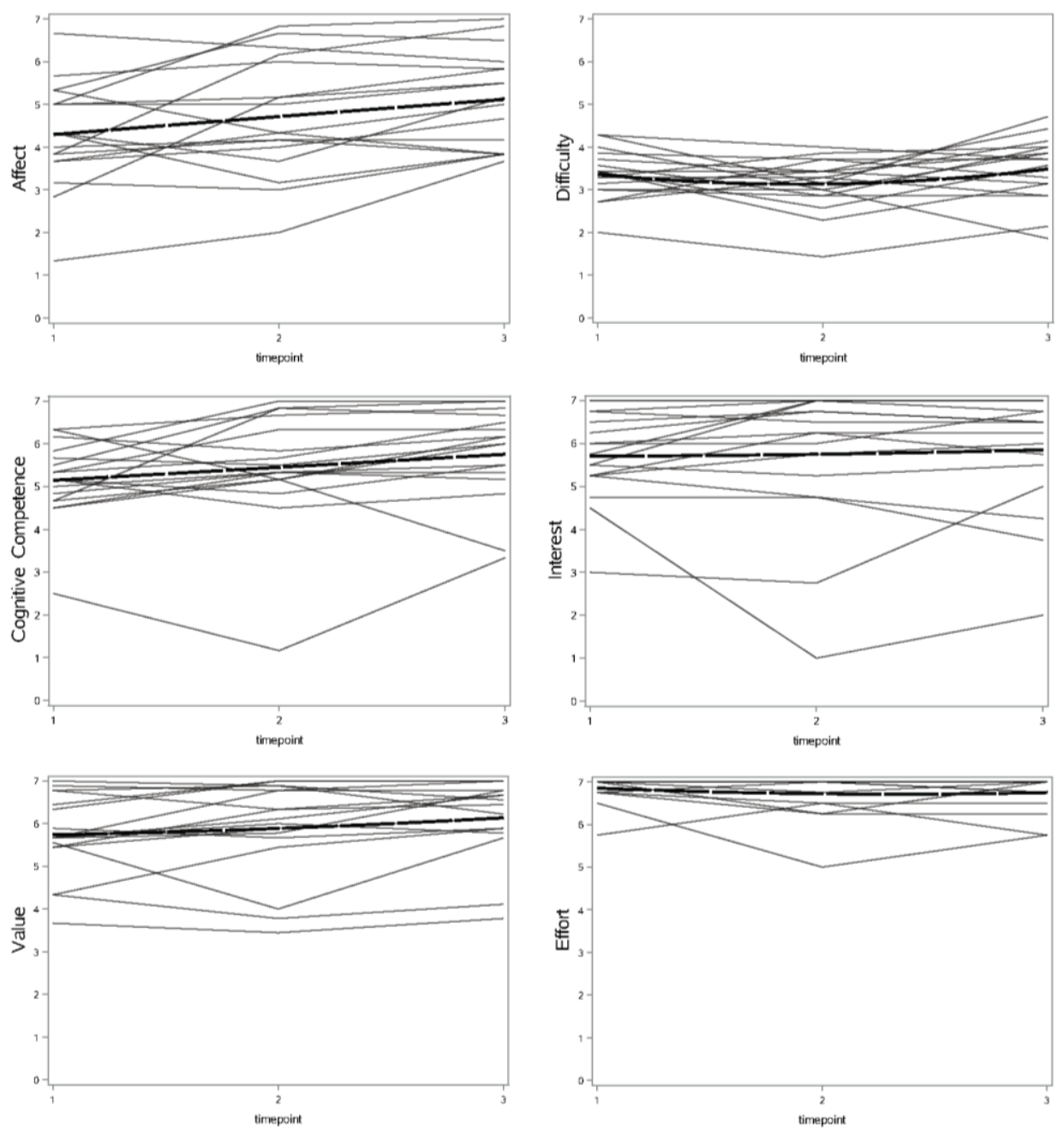

Figure 2. Spaghetti plots of attitudes toward statistics (affect, cognitive competence, value, difficulty, interest, and effort) over time

Figure Note. Only students who provided data at all three time points for a given measure are included in the plots to depict individual change patterns. Two students who dropped the course and one student who was absent at Time 2 were excluded from each plot due to missing data. The sample size, therefore, for each plot is $n=17$. In each plot, the dashed bold line represents the central tendency spline. 
Growth Mindsets and Final Course Grades The mean final grade for all 18 participants was $88.28 \%$ ( $S D=8.48$ ), with scores ranging from $75 \%$ to $100 \%$. Contrary to our hypothesis (ii) that students' growth mindsets would be positively associated with academic outcomes, calculated final grade and growth mindset score at Time 1 were negatively correlated, as shown in Figure 3. However, the majority of students' growth mindset scores fell in the top half of the score range, causing a broad spread in the right half of the plot. There was no correlation between calculated final grade and growth mindset score at Time 2, as shown in Figure 4. Note that grade has a ceiling effect. Similarly, Figure 5 shows the lack of correlation between calculated final grade and growth mindset score at Time 3 .

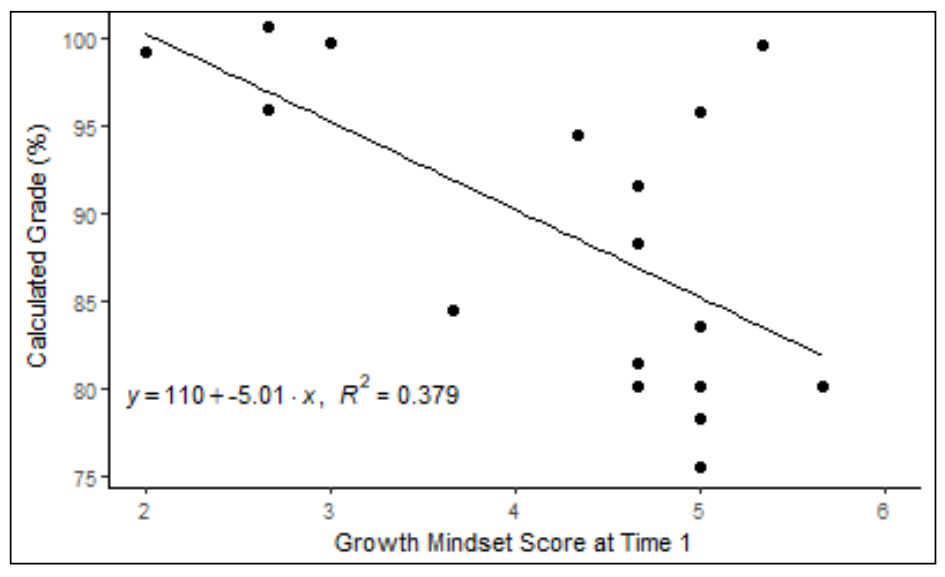

Figure 3. Growth mindset score at time 1 and final grade

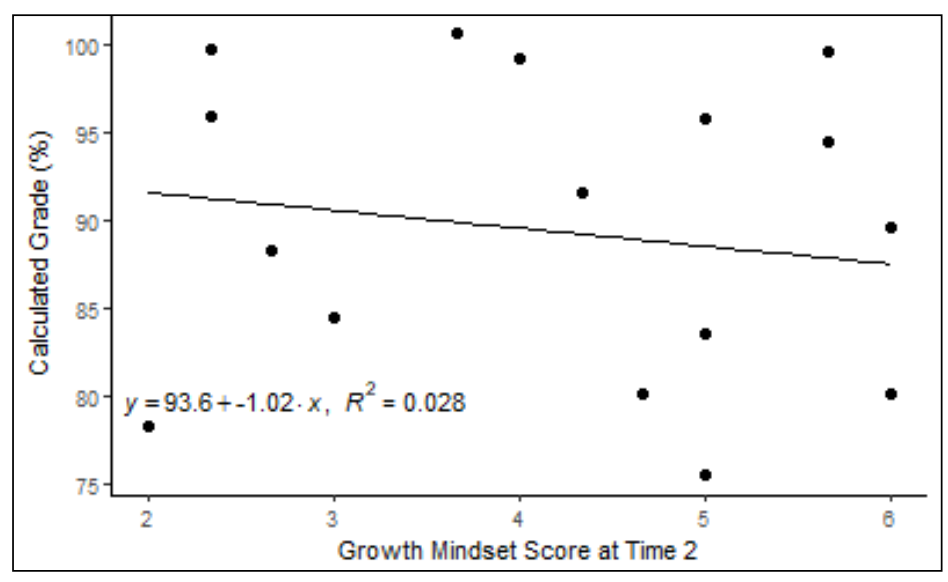

Figure 4. Growth mindset score at time 2 and final grade

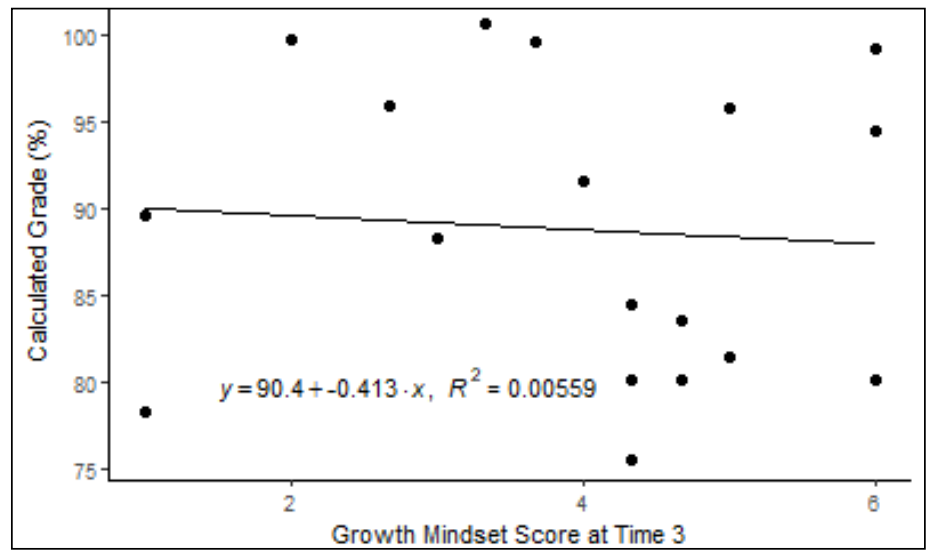

Figure 5. Growth mindset score at time 3 and final grade 
Acceptability, Feasibility, and Utility of the Pilot Intervention Project Overall, the project was highly rated by participants, supporting our hypothesis (iii) that students' perceptions of the acceptability, feasibility, and utility of the intervention would be positive. The mean score for the Acceptability, Feasibility, Utility measure was $38.59(S D=4.65)$ out of a possible 45 points. Almost all $(n=17,94 \%)$ of the 18 students who participated in the Time 3 survey completed the acceptability, feasibility, and utility survey. Eleven students responded positively ("Very much" or "Totally") to each item regarding the growth mindset materials, namely "the growth mindset materials were relevant to my particular needs" and "the materials/handouts/resources were of good quality and useful." Fifteen students responded positively to two of the three items regarding the use of the intervention project throughout the course and the professor's presentation of growth mindset materials, including "this course was based on a growth mindset philosophy" and "I found the professor's presentation of materials related to growth mindset to be useful." Similarly, 15 students responded positively to two of the three items regarding their own opinion of the intervention project and the growth mindset, When considering the psychoeducation activities implemented during the course, seven students found the psychoeducation activities "very much" or "totally" effective in helping them learn course material.

A descriptive sub-analysis was conducted on the 11 respondents who reported that the intervention was either "very much" or "totally" relevant to their particular needs. Demographically, this subgroup was slightly younger $(M=26.18, S D=5.00)$, and disproportionately white $(50 \%)$ and male $(27.27 \%)$ compared to the larger group. This subgroup had mean scores for growth mindset and covitality that were comparable to the larger respondent sample, with the exception of grit scores, which had means of $2.70(S D=0.40), 2.69(S D=0.36)$, and $2.72(S D=0.36)$ at time points 1,2 , and 3 , respectively. The subgroup had completed less coursework in general than the larger respondent sample $(M=5.90, S D=$ 5.79 versus $M=7.00, S D=5.48$ ), but had similar levels of exposure to previous coursework in mathematics and statistics ( $M=5.00$ for both, $S D=2.09-2.40)$. The final mean grade for the subgroup was $88.90 \%$, compared to the larger sample mean of $88.28 \%$.

The Acceptability, Feasibility, and Utility survey additionally included four open-ended questions. When asked "Which psychoeducation and/or open task activity did you find most valuable?" students' responses included "listing of ways to accomplish goals" and "hearing the presentation on growth mindset and how it applied to personal hardships," with the most valuable activity (mentioned by three students) being the open discussion on reframing failure as an opportunity for growth. When asked "How have the growth mindset materials helped increase your comprehension of the course topics?" students' responses were positive: "It's given me the ability to believe in myself," "encouraged me to be more positive in my ability to do well," and "it's helped me think about my approach differently instead of skipping over materials or giving up." When asked "Do you have any suggestions for improving the growth mindset materials?" students' responses included: "Point out that the term intelligence is used in a very specific way in GM materials," "increase content so it is included in all lectures," and "perhaps present even more materials."

\section{DISCUSSION}

To our knowledge, this study represents the first project to administer a growth mindset intervention to graduate-level biostatistics students and to measure subsequent outcomes during and after the intervention. Overall, students reported some positive mean changes in their attitudes toward statistics, with limited changes in their growth mindset, grit, and covitality. These results did not support our hypothesis (i) that students' self-assessed growth mindset, grit, social and emotional health (i.e., covitality) would improve over time. However, attitudes toward statistics did improve over time. Further, hypothesis (ii) was not supported, growth mindset scores were not positively related to final grades. Finally, hypothesis (iii) was supported. Students did find the growth mindset intervention to be acceptable, feasible, and useful. Below, we discuss specific findings in detail.

Surprisingly, students' growth mindset scores did not increase over time. This may be partially because students in our study reported relatively high initial growth mindset scores (i.e., at Time 1, growth mindset $M=4.46, S D=1.13$ ). This is higher than summary scores presented in previous studies investigating growth mindsets among college students. For example, Aditomo (2015) used the same measure of growth mindset and obtained average growth mindset scores of $4.00(S D=0.77)$ in a sample of college students. This indicates that students in our study attended the class with an already high 
level of growth mindset. Of note, the growth mindset scale's upper limit is 6 , so there was limited room for growth mindset scores to improve over the course of the study. It is possible that our student population had a high initial growth mindset level because they were graduate students. Growth mindset affinities may be higher among those who pursue graduate education; this is an important question to explore in future research.

Students' levels of grit remained relatively constant over the course of this pilot intervention. Levels of student grit in our study were comparable to those previously reported in higher education among pharmacy students (Pate et al., 2017), though lower than those among online master's students (Milman, Posey, Pintz, Wright, \& Zhou, 2015). The intervention that was the focus of this study seems to have had a minimal short-term effect on students' perseverance.

Students' social and emotional health, as measured through covitality, remained, on average, the same throughout the study. Covitality has seldom been assessed at the graduate level, but compared to studies among undergraduates (Furlong et al., 2016), our sample of students reported slightly higher baseline scores. Interventions for graduate students that yield mental health benefits are of particular importance given increasing reports of mental health crises at the graduate level (Evans, Bira, BeltranGastelum, Weiss, \& Vanderford, 2017; Moffitt et al., 2014); however, we did not find evidence that the intervention in this study might improve covitality.

With regard to attitudes toward statistics, students in this pilot study reported mean improvements in their feelings toward statistics, abilities related to statistics, interest in statistics, and their impressions of the importance of statistics in their personal and professional lives. The largest changes were observed in relation to affect, which measures students' emotions about statistics (Schau, 2003), and cognitive competence. Compared to some recent research, however, participants in this study reported higher baseline scores for positive attitudes related to five of the six SATS-36 subscales (i.e., affect, cognitive competence, value, interest, and effort; Hannigan, Hegarty \& McGrath, 2014; Kiekkas et al., 2015). In those studies, participants' levels of perceived difficulty associated with statistics were the same or higher than that observed in our study at Time 1 (Hannigan et al., 2014; Kiekkas et al., 2015). As Schau and Emmioğlu (2012) pointed out, in cases where the mean score for a subscale of student attitudes toward statistics is high to begin with, there is little room for the upward mobility that may result from a successfully implemented intervention (Schau \& Emmioğlu, 2012). In this study, inculcation of the growth mindset approach, in conjunction with course materials, may have helped students feel more favorably about statistics and reduced negative feelings such as fear. The degree to which the implementation of the growth mindset intervention specifically contributed to these attitude changes, however, is an important question to be explored in future research. Recent literature on the extent to which participating in a statistics course impacts attitudes, independently of other factors, is mixed: Schau \& Emmioğlu (2012) found that statistics courses, in and of themselves, may be insufficient to cultivate or sustain positive attitudes towards statistics, whereas Kerby Wroughton (2017) found that students of statistics courses may experience changes in their attitudes toward statistics as a byproduct of taking the course itself.

In this study, higher growth mindset scores were not related to higher grades, contrary to our hypothesis (ii) that students' growth mindsets would be positively associated with academic outcomes. Students with higher growth mindset scores at Time 1 (baseline) went on to earn lower grades in the class, and there was essentially no relationship between final grades and growth mindset scores at Time 2 or Time 3. This was surprising, given that past research has connected growth mindsets with academic achievement among youth (Blackwell et al., 2007; Bostwick, Collie, Martin, \& Durksen, 2017; Good et al., 2003), though this has not been found consistently across studies (e.g., Dommett, Devonshire, Sewter, \& Greenfield, 2013; Orosz, Péter-Szarka, Bőthe, Tóth-Király, \& Berger, 2017; Bahník \& Vranka, 2017). The discrepancy between self-reported growth mindset at baseline and final grades in this statistics course may be attributable to a discrepancy in growth mindsets about intelligence in general, versus mindsets about mathematical or statistical ability. There is some debate in the growth mindset and incremental intelligence community about whether domain-specific measures of growth mindset are more appropriate than generalized measures of attitudes toward intelligence as a whole (Tarbetsky, Collie, \& Martin, 2016). Another possible explanation for the discrepancy between selfreported growth mindset at baseline and final grades in this statistics course is related to the age ranges of participants in previous studies compared to the age range observed in this study; as previously discussed, much prior work has focused on youth (Blackwell et al., 2007; Bostwick et al., 2017; Good 
et al., 2003), and graduate students are far removed from that age group. In addition, it should be noted that activities were time limited with regard to duration, which may explain these results. Although further studies are needed in this area, our results are a potential preliminary indicator that growth mindset interventions may be less academically impactful for graduate-level students in terms of final course grades.

Our final aim of this study was to evaluate the acceptability, feasibility, and utility of this growth mindset intervention in a graduate course. On average, students responded positively to the ideas and program as delivered, supporting our hypothesis (iii) that students' perceptions of the acceptability, feasibility, and utility of the intervention would be positive. The lowest response (for utility of the materials) indicates that the materials and methods can be refined over time. In support of this, the qualitative feedback on the most useful aspects of the growth mindset pilot intervention reveals areas of focus for expansions of this approach in graduate education. Students specifically cited the value of discussions regarding resilience amidst setbacks, practice with goal-setting, and opportunities to relate growth mindsets back to personal experience. Furthermore, the feedback students provided regarding ways to improve intervention materials underscored the acceptability of the intervention activities. Many students recommended an even deeper integration of the growth mindset materials with the course, with two students recommending that additional time be spent on explaining aspects of attitudes toward intelligence. Importantly, several students noted that the intervention was personally meaningful for them. Additionally, our sub-analysis revealed that the students who did report that the intervention was relevant to them had lower levels of grit throughout the study compared with the larger groupmore than a standard deviation below the larger group's mean at each time point. This suggests that such approaches may be most readily accepted by those students who are low in perseverance, even if the impacts of the intervention are not immediately palpable in terms of final grades.

This pilot intervention had several limitations. First, our study included 20 students. Due to this small sample size, we only presented descriptive information in our study. Further, activities may not generalize to other settings outside of public health. It is also important to note that one of the measures we used, the SEHS-HE, had not previously been used among graduate students as of the inception of the study. We posit, however, that the students in our sample, the majority of whom were first-year students in a new graduate program, were likely to have been experiencing similar transitional pressures as students from the samples in prior studies. In addition, information on participants' prior exposure to mathematics and statistics coursework was limited to a self-reported number of courses differentiable by level of education, but not specific subject (i.e., mathematics or statistics), which impairs our ability to draw conclusions between this factor and grades at the end of the study. Another limitation was that the study itself was restricted to a single semester, rendering us unable to track any long-term changes in academic performance or mindset. Follow-up time to assess the effectiveness of growth mindsetoriented interventions has in previous studies ranged from three weeks (Bettinger, Ludvigsen, Rege, Ingeborg, \& Yeager, 2018) to three months (Kassaee, 2017); however, the sufficient timeframe for a successful intervention at the graduate level in statistics is at this point unknown. In addition, intervention activities in this study were limited in duration. Although we viewed this as a strength of the activities as it relates to later replication and implementation, this is a possible reason for the limited results of this study. Finally, delivery and effectiveness of the growth mindset intervention is likely instructor-dependent (Schmidt, Shumow, \& Kackar-Cam, 2015).

The findings from this study provide important preliminary information for educators to improve student outcomes related to learning statistics at the graduate level. Based on these results, incorporating growth mindset instruction and activities into courses shows promise for statistical education in a public health setting. Although the data show limited empirical relationships between growth mindset and grades, students reported that the intervention was clinically meaningful for them. In light of the low cost and effort required to implement a growth mindset intervention, this approach is worth considering for those who teach graduate-level statistics courses. Although this approach warrants further research, findings from this pilot study indicate that students would likely be open to growth mindset interventions, and that what they learn about the growth mindset may be useful to them beyond statistics. Educators may thus wish to incorporate these approaches in courses that have historically been challenging, but that students generally take early on in their graduate career. 


\section{ACKNOWLEDGEMENTS}

The authors would like to gratefully acknowledge the students who participated in this study. In addition, Ryan Savage and Richard Ortiz provided valuable feedback on drafts of this manuscript.

\section{REFERENCES}

Aditomo, A. (2015). Students' responses to academic setback: "Growth mindset" as a buffer against demotivation. International Journal of Educational Psychology, 4(2), 198-222.

Aronson, J., Fried, C. B., \& Good, C. (2002). Reducing the effects of stereotype threat on African American college students by shaping theories of intelligence. Journal of Experimental Social Psychology, 38(2), 113-125.

[Online: https://doi.org/10.1006/jesp.2001.1491 ]

Bahník, Š., \& Vranka, M. A. (2017). Growth mindset is not associated with scholastic aptitude in a large sample of university applicants. Personality and Individual Differences, 117, 139-143.

[Online: https://doi.org/10.1016/J.PAID.2017.05.046 ]

Bäuml, J., Froböse, T., Kraemer, S., Rentrop, M., \& Pitschel-Walz, G. (2006). Psychoeducation: A basic psychotherapeutic intervention for patients with schizophrenia and their families. Schizophrenia Bulletin, 32(Suppl 1), S1-S9.

[Online: https://doi.org/10.1093/schbul/sbl017 ]

Bettinger, E., Ludvigsen, S., Rege, M., Ingeborg, S., \& Yeager, D. (2018). Increasing perseverance in math: Evidence from a field experiment in Norway. Journal of Economic Behavior \& Organization, 146(2018), 1-15.

[Online: https://doi.org/10.1016/j.jebo.2017.11.032 ]

Blackwell, L. S., Trzesniewski, K. H., \& Dweck, C. S. (2007). Implicit theories of intelligence predict achievement across an adolescent transition: A longitudinal study and an intervention. Child Development, 78(1), 246-263. [https://doi.org/10.1111/j.1467-8624.2007.00995.x ]

Bostwick, K. P., Collie, R. J., Martin, A. J., \& Durksen, T. L. (2017). Students' growth mindsets, goals, and academic outcomes in mathematics. Zeitschrift Für Psychologie, 225(2), 107-116. [Online: https://doi.org/10.1027/2151-2604/a000287 ]

Bryan University. (2016, January 21). Fixed Mindset Vs. Growth Mindset [Video File]. [Online: https://www.youtube.com/watch?v=Xv2ar6AKvGc ]

Casleton, E., Beyler, A., Genschel, U., \& Wilson, A. (2014). A pilot study teaching metrology in an introductory statistics course. Journal of Statistics Education, 22(3). [Online: https://doi.org/10.1080/10691898.2014.11889710 ]

Chew, P. K., \& Dillon, D. B. (2014). Statistics anxiety update: Refining the construct and recommendations for a new research agenda. Perspectives on Psychological Science, 9(2), 196208.

[Online: https://doi.org/10.1177/1745691613518077 ]

Davis, M. V., Dandoy, S., \& Greaves, W. W. (2003). Graduate programs: What is their contribution to the training of the public health workforce? American Journal of Preventive Medicine, 24(4), 361366.

[Online: https://doi.org/10.1016/S0749-3797(03)00016-3]

Domitrovich, C. E., Durlak, J. A., Staley, K. C., \& Weissberg, R. P. (2017). Social-emotional competence: An essential factor for promoting positive adjustment and reducing risk in school children. Child Development, 88(2), 408-416.

Dommett, E. J., Devonshire, I. M., Sewter, E., \& Greenfield, S. A. (2013). The impact of participation in a neuroscience course on motivational measures and academic performance. Trends in Neuroscience and Education, 2(3), 122-138.

[Online: https://doi.org/10.1016/j.tine.2013.05.002 ]

Duckworth, A. L., Peterson, C., Matthews, M. D., \& Kelly, D. R. (2007a). Grit: Perseverance and passion for long-term goals. Journal of Personality and Social Psychology, 92(6), 1087-1101.

[Online: https://doi.org/10.1037/0022-3514.92.6.1087 ] 
Duckworth, A. L., Peterson, C., Matthews, M. D., \& Kelly, D. R. (2007b). Grit Scale [Database record]. Retrieved from PsycTESTS.

[Online: https://doi.org/10.1037/t07051-000 ]

Duckworth, A. L., \& Quinn, P. D. (2009). Development and validation of the Short Grit Scale (Grit-S). Journal of Personality Assessment, 91(2), 166-174.

Durlak, J. A., Weissberg, R. P., Dymnicki, A. B., Taylor, R. D., \& Schellinger, K. B. (2011). The impact of enhancing students' social and emotional learning: A meta-analysis of school-based universal interventions. Child Development, 82(1), 405-432.

Dweck, C. (2010). How can you change from a fixed mindset to a growth mindset? [Online: http://mindsetonline.com/changeyourmindset/firststeps/index.html ]

Dweck, C. S., Chiu, C.-Y., \& Hong, Y.-Y. (1995). Implicit theories and their role in judgments and reactions: A world from two perspectives. Psychological Inquiry, 6(4), 267-285.

Eskreis-Winkler, L., Shulman, E. P., Beal, S. A., \& Duckworth, A. L. (2014). The grit effect: Predicting retention in the military, the workplace, school and marriage. Frontiers in Psychology, 5(36), 1-12. [Online: https://doi.org/10.3389/fpsyg.2014.00036 ]

Evans, B. (2007). Student attitudes, conceptions, and achievement in introductory undergraduate college statistics. The Mathematics Educator, 17(2), 24-30.

Evans, T. M., Bira, L., Beltran-Gastelum, J., Weiss, L. T., \& Vanderford, N. (2017). Mental health crisis in graduate education: The data and intervention strategies. Federation of American Societies for Experimental Biology Journal, 31(1), 750-757.

Fitzgerald, C. J., \& Laurian-Fitzgerald, S. (2016). Helping students enhance their grit and growth mindsets. Journal Plus Education, 14, 52-67.

Furlong, M. J., You, S., Shishim, M., \& Dowdy, E. (2016). Development and validation of the Social Emotional Health Survey-Higher Education Version. Applied Research in Quality of Life, 12(2), $1-25$.

[Online: https://doi.org/10.1007/s11482-016-9464-9 ]

Gal, I., \& Ginsburg, L. (1994). The role of beliefs and attitudes in learning statistics: Towards an assessment framework. Journal of Statistics Education, 2(2). [Online: https://doi.org/10.1080/10691898.1994.11910471 ]

Good, C., Aronson, J., \& Inzlicht, M. (2003). Improving adolescents' standardized test performance: An intervention to reduce the effects of stereotype threat. Applied Developmental Psychology, 24, $645-662$.

Hannigan, A., Hegarty, A. C., \& McGrath, D. (2014). Attitudes towards statistics of graduate entry medical students: The role of prior learning experiences. BMC Medical Education, 14(1), 70.

Hochanadel, A., \& Finamore, D. (2015). Fixed and growth mindset in education and how grit helps students persist in the face of adversity. Journal of International Education Research, 11(1), 4750.

Kassaee, A. M. (2017). Examining the role of motivation and mindset in the performance of college students majoring in STEM fields. Dissertation Abstracts International Section A: Humanities and Social Sciences, 77(12-A)(E).

Kerby, A., \& Wroughton, J. (2017). When do students' attitudes change? Investigating student attitudes at midterm. Statistics Education Research Journal, 16(2), 476-486. [Online: https://iase-web.org/documents/SERJ/SERJ16(2)_Kerby.pdf ]

Kiekkas, P., Panagiotarou, A., Malja, A., Tahirai, D., Zykai, R., Bakalis, N., \& Stefanopoulos, N. (2015). Nursing students' attitudes toward statistics: Effect of a biostatistics course and association with examination performance. Nurse Education Today, 35, 1283-1288.

[Online: https://doi.org/10.1016/j.nedt.2015.07.005 ]

Krause, M. (2017, June 19). Ira Glass on storytelling part 3 of 4 [Video File]. [Online: https://vimeo.com/222197198 ]

Lemov, D. (2015). Teach like a champion 2.0: 62 techniques that put students on the path to college. San Francisco, CA: Jossey-Bass.

Moffitt, L. B., Garcia-Williams, A., Berg, J. P., Calderon, M. E., Haas, A. P., \& Kaslow, N. J. (2014). Reaching graduate students at risk for suicidal behavior through the Interactive Screening Program. Journal of College Student Psychotherapy, 28(1), 23-34. [Online: http://doi.org/10.1080/87568225.2014.854675 ] 
Milman, N. B., Posey, L., Pintz, C., Wright, K., \& Zhou, P. (2015). Online master's students' perceptions of institutional suports and resources: Initial survey results. Online Learning, 19(4). [Online: https://doi.org/10.24059/olj.v19i4.549]

Nolan, M. M., Beran, T., \& Hecker, K.G. (2012). Surveys assessing students' attitudes toward statistics: A systematic review of validity and reliability. Statistics Education Research Journal, 11(2), 103123.

[Online: https://iase-web.org/documents/SERJ/SERJ11(2)_Nolan.pdf]

Onwuegbuzie, A. J. (2003). Modeling statistics achievement among graduate students. Educational and Psychological Measurement, 63(6), 1020-1038.

[Online: https://doi.org/10.1177/0013164402250989 ]

Onwuegbuzie, A. J., \& Wilson, V. A. (2003). Statistics anxiety: Nature, etiology, antecedents, effects, and treatments-A comprehensive review of the literature. Teaching in Higher Education, 8(2), 195-209.

Orosz, G., Péter-Szarka, S., Bőthe, B., Tóth-Király, I., \& Berger, R. (2017). How not to do a mindset intervention: Learning from a mindset intervention among students with good grades. Frontiers in Psychology, 8, 311.

[Online: https://doi.org/10.3389/fpsyg.2017.00311 ]

Pate, A., Payakachat, N., Harrell, T. K., Pate, K. A., Caldwell, D. J., \& Franks, A. M. (2017). Measurement of grit and correlation to student pharmacist academic performance. American Journal of Pharmaceutical Education, 81(6), 1-8.

Paunesku, D., Walton, G. M., Romero, C., Smith, E. N., Yeager, D. S., \& Dweck, C. S. (2015). Mindset interventions are a scalable treatment for academic underachievement. Psychological Science, 26(6), 784-793.

Rossen, E., \& Oakland, T. (2008). Graduate preparation in research methods: The current status of APA-accredited professional programs in psychology. Training and Education in Professional Psychology, 2(1), 42-49.

[Online: https://doi.org/10.1037/1931-3918.2.1.42 ]

Schau, C. (2003). Survey of Attitudes Towards Statistics (SATS-36).

[Online: http://evaluationandstatistics.com ]

Schau, C., \& Emmioğlu, E. (2012). Do introductory statistics courses in the United Statesimprove students' attitudes? Statistics Education Research Journal, 11(2), 86-94. [Online: https://iase-web.org/documents/SERJ/SERJ11(2)_Schau.pdf]

Schmidt, J. A., Shumow, L., \& Kackar-Cam, H. (2015). Exploring teacher effects for mindset intervention outcomes in seventh-grade science classes. Middle Grades Research Journal, 10(2), $17-32$.

Shin, E. H. (1975). Statistics requirements for undergraduate sociology majors in colleges and universities in the United States. The American Sociologist, 10(2), 92-102.

Tarbetsky, A. L., Collie, R. J., \& Martin, A. J. (2016). The role of implicit theories of intelligence and ability in predicting achievement for Indigenous (Aboriginal) Australian students. Contemporary Educational Psychology, 47, 61-71.

[Online: https://doi.org/10.1016/j.cedpsych.2016.01.002 ]

Taylor, R. D., Oberle, E., Durlak, J. A., \& Weissberg, R. P. (2017). Promoting positive youth development through school-based social and emotional learning interventions: A meta-analysis of follow-up effects. Child Development, 88(4), 1156-1171.

[Online: https://doi.org/10.1111/cdev.12864]

Tempelaar, D. T., van der Loeff, S. S., \& Gijselaers, W. H. (2007). A structural equation model analyzing the relationship of students' attitudes toward statistics, prior reasoning abilities and course performance. Statistics Education Research Journal, 6(2), 78-102.

[Online: https://www.stat.auckland.ac.nz/ iase/serj/SERJ6(2)_Tempelaar.pdf ]

Williams, J. D., Livings, M. S., Cathey, R. J., \& Lai, B. S. (2018). Employing a growth mindset intervention in a graduate level statistics course: Merging research with teaching. SAGE Research Methods Cases.

[Online: https://doi.org/10.4135/9781526449122 ]

Yan, V. X., Thai, K.-P., \& Bjork, R. A. (2014). Habits and beliefs that guide self-regulated learning: Do they vary with mindset? Journal of Applied Research in Memory and Cognition, 3(3), 140-152. 
[Online: https://doi.org/10.1016/j.jarmac.2014.04.003 ]

Yeager, D. S., Romero, C., Paunesku, D., Hulleman, C. S., Schneider, B., Hinojosa, C., ... Dweck, C. S. (2016). Using design thinking to improve psychological interventions: The case of the growth mindset during the transition to high school. Journal of Educational Psychology, 108(3), 374-391. [Online: https://doi.org/10.1037/edu0000098 ]

You, S., Furlong, M. J., Dowdy, E., Renshaw, T. L., Smith, D. C., \& O’Malley, M. D. (2014). Further validation of the Social and Emotional Health Survey for high school students. Applied Research in Quality of Life, 9(4), 997-1015.

Zonnefeld, V. (2015). Mindsets, attitudes, and achievement in undergraduate statistics courses. Dissertation Abstracts International Section A: Humanities and Social Sciences, 76/12(E).

BETTY S. LAI

Department of Counseling, Developmental, and Educational Psychology

Lynch School of Education

Boston College

USA 